\title{
Altered capsaicin levels in domesticated chili pepper varieties affect the interaction between a generalist herbivore and its ectoparasitoid
}

\author{
Yosra Chabaane $^{1} \cdot$ Carla Marques Arce ${ }^{2} \cdot$ Gaëtan Glauser $^{3} \cdot$ Betty Benrey $^{1}$ (D)
}

Received: 23 February 2021 / Revised: 31 May 2021 / Accepted: 8 June 2021 / Published online: 25 June 2021

(c) The Author(s) 2021

\begin{abstract}
Plant domestication has commonly reduced levels of secondary metabolites known to confer resistance against insects. Chili pepper is a special case because the fruits of different varieties have been selected for lower and higher levels of capsaicin, the main compound associated with defence. This may have important consequences for insect herbivores and their natural enemies. Despite the widespread consumption of chili peppers worldwide, the effects of capsaicin on insects are poorly understood. Here, we investigated the effect of capsaicin on a generalist herbivore, Spodoptera latifascia (Lepidoptera: Noctuidae) and its ectoparasitoid, Euplectrus platyhypenae (Hymenoptera: Eulophidae). Using chili varieties with three pungency levels: non-pungent (Padron), mild (Cayenne) and highly pungent (Habanero), as well as artificial diets spiked with three different levels of synthetic capsaicin, we determined whether higher capsaicin levels negatively affect the performance of these insects. Overall, capsaicin had a negative effect on both herbivore and parasitoid performance, particularly at high concentrations. Caterpillars reared on highly pungent fruits and high-capsaicin diet had longer development time, reduced pupation success, lower adult emergence, but also lower parasitism rates than caterpillars reared on mild or non-capsaicin treatments. In addition, we found that the caterpillars were capable of sequestering capsaicinoids in their haemolymph when fed on the high pungent variety with consequences for parasitoids' performance and oviposition decisions. These results increase our understanding of the role of capsaicin as a chemical defence against insects and its potential implications for pest management.
\end{abstract}

Keywords Chili pepper · Domestication · Capsaicinoids $\cdot$ Plant-mediated $\cdot$ Sequestration $\cdot$ Tritrophic interactions

\section{Key message}

- Domestication of chili peppers has altered the content of capsaicin in fruits, which is responsible for the chili's pungency.

Communicated by Antonio Biondi.

Betty Benrey

betty.benrey@unine.ch

1 Laboratory of Evolutionary Entomology, Institute of Biology, University of Neuchâtel, Rue Emile-Argand 11, 2000 Neuchâtel, Switzerland

2 Fundamental and Applied Research in Chemical Ecology, Institute of Biology, University of Neuchâtel, Rue Emile-Argand 11, 2000 Neuchâtel, Switzerland

3 Neuchâtel Platform of Analytical Chemistry, Institute of Chemistry, University of Neuchâtel, Rue Emile-Argand 11, 2000 Neuchâtel, Switzerland
- Capsaicin has been associated with defense against insects, but the evidence is limited.

- We tested the effects of capsaicin on a generalist herbivore and its parasitoid.

- Capsaicin had negative effects on herbivore performance, cascading up to the parasitoid.

- The results support the role of capsaicin as a chemical defense against insects, with possible implications for pest management.

\section{Introduction}

Plant domestication has resulted in a suite of morphological, nutritional and chemical traits that distinguish crops from their wild counterparts (Gepts 2004; Smartt and Simmonds 1995). One of the main changes in crops is a reduction in secondary metabolites (Meyer et al. 2012). The reason for this change is to render plants more suitable for human 
consumption (Ladizinsky 2012). In this context, chili pepper (Capsicum spp., family Solanaceae) offers a unique model to examine the relationship between domestication and altered levels of chemical defences.

The genus Capsicum is resolved as a monophyletic group with five domesticated taxa and around 20-30 wild species (Carrizo García et al. 2016). In contrast to most crop plants for which domestication has resulted in a decrease of secondary metabolites, chili peppers have been selected for both increased and decreased levels of their main secondary metabolites so-called capsaicinoids (Aza-González et al. 2011; Kim 2014) as compared to the wild ancestor, Chiltepin (González-Zamora et al. 2015; Tewksbury et al. 2008). These secondary compounds are biosynthesized and accumulated in the placenta tissue and responsible for the pungency or spiciness in chili fruits (Pickersgill 2016). The varietal selection was performed along a gradient from low to high pungency (from 0 to 1,500,000 Scoville units) (Scoville 1912). The main capsaicinoids are capsaicin and dihydrocapsaicin which represent $90 \%$ of the whole capsaicinoids in fruits (Govindarajan and Salzer 1985). Capsaicinoids are synthetized via two different pathways, the phenylpropanoid and the branched-chain fatty acid pathways (Aza-González et al. 2011), and two genes were identified to be responsible for chili pepper pungency, Pun1 and pAMT located, respectively, on chromosome 2 and chromosome 3 (Lang et al. 2006; Stewart Jr et al. 2005). The unfunctional alleles of these genes cause the loss of pungency found in sweet pepper varieties (Tsurumaki and Sasanuma 2019).

Capsaicinoids are known to have deterrent and medicinal properties for mammals. For example, chili has been used as a crop guarding system in different African and Asian countries to reduce human-elephant conflicts (Chang'a et al. 2016; Hedges and Gunaryadi 2010). Interestingly, birds are not sensitive to capsaicin (Mason and Maruniak 1983; Szolcsányi et al. 1986). A comparison between chicken capsaicin vanilloid receptors (cTRPV19) and its rat counterparts (rTRPV1) showed a high structural divergence (only 68\% amino acid identity) (Jordt and Julius 2002). The difference between both vanilloid receptors might be the result of selective pressures that facilitate the differentiation of the ecological niche of each species. Indeed, it has been suggested that birds evolved as vectors for fruit dispersion whereas mammals were repelled to avoid the destruction of seeds (Tewksbury and Nabhan 2001; Tewksbury et al. 2008). Chili has been also known for its medicinal uses long before the Spanish colonization of the Americas and since the Mayan civilization (Cichewicz and Thorpe 1996; Pickersgill 2016; Witting et al. 2000).

The effect of capsaicin on pathogenic bacteria and fungi has also been widely studied. Capsaicin inhibits and retards the growth of several human (e.g. Helicobacter pylori, Escherichia coli, Streptococcus pyogenes), soil (e.g. Bacillus subtilis and Pseudomonas solanacearum) and plant pathogenic (e.g. Xanthomonas campestris, Pseudomonas syringae) bacteria (Argaez et al. 2009; Jones et al. 1997; Marini et al. 2015; Molina-Torres 1999). For example, non-pungent wild chili fruits were twice more infested by Fusarium spp. as compared to wild pungent fruits, suggesting that capsaicinoids protect fruits from pathogenic fungi (Haak et al. 2012; Tewksbury et al. 2008). Likely, the reason why hot chilies have been used for food preservation in many regions, long before the use of refrigerators (Omolo 2014).

For insects, there is a common assumption that capsaicin is toxic. Several studies have shown that capsaicin deters oviposition (Cowles et al. 1989), slows down larval development (Ahn et al. 2011a; Weissenberg et al. 1986) and inhibits feeding (Hori et al. 2011). Moreover, synthetic capsaicin has even been used as a pesticide against some insect pests (wilsonKoleva-Gudeva et al. 2013; Wilson 1996). Although the above studies demonstrate the negative effects of capsaicin on insect herbivores, they were all conducted using either artificial diet in which pure capsaicin or dried chili powder was added. As yet, only a handful study have examined the effect of capsaicin on insect herbivores using fresh fruits (Tęgowska et al. 2005).

Plant secondary metabolites can also affect the natural enemies of herbivores in different ways (Chen et al. 2015; Turlings and Benrey 1998). For example, parasitoid wasps can benefit from the volatiles emitted from herbivore-damaged plants and use them as cues to find their host (Turlings et al. 1990; Vet and Dicke 1992). In addition, secondary metabolites can slow down herbivore development and thus increase their time of exposure to natural enemies (Benrey and Denno 1997; Price et al. 1980). Alternatively, some herbivores can sequester and store plant toxins in their bodies making them unpalatable or toxic for their natural enemies (Opitz and Müller 2009; Rowell-Rahier and Pasteels 1992). For example, El-Heneidy et al. (1988) found that the survival of an Ichneumonid parasitoid (Hyposoter annulipes) (Hymenoptera: Ichneumonidae) was reduced when its larval host, the fall armyworm (Spodoptera frugiperda) (Lepidoptera: Noctuidae), was fed on artificial diet mixed with nicotine. In another study, it was shown that by sequestering alkaloids from its host plant, larvae of the sawfly (Rhadinoceraea nodicornis) (Hymenoptera, Tenthredinidae) were protected against generalist predators (Schaffner et al. 1994). To date, however, the effects of capsaicin on the natural enemies of herbivores are not known. Knowing whether capsaicin has a negative effect on insect herbivores and these effects cascade up to their natural enemies is a valuable information for pest management practices of chili pepper.

The aim of this study was to examine how altered capsaicin levels in chili peppers as a result of varietal selection affect the tritrophic interaction with a generalist herbivore Spodoptera latifascia (Lepidoptera: Noctuidae) and one of 
its larval ectoparasitoid, Euplectrus platyhypenae (Hymenoptera: Eulophidae). We used a combination of chemical analyses and behavioural assays to address the following questions: (1) is capsaicin toxic for these insects? and (2) what are the direct and indirect (via the host caterpillar) effects of capsaicin on herbivore and parasitoid performance? To answer these, first we determined capsaicin levels in fruits of three varieties selected for different pungency levels. Secondly, we reared herbivores on fruits of these varieties, as well as parasitoids on caterpillars fed with these fruits and determined their performance, and finally, we reared parasitized and non-parasitized caterpillars on artificial diet with different levels of synthetic capsaicin.

Our results provide insight into how varietal selection of this important crop has influenced its interactions with herbivores and their parasitoids. Furthermore, to our knowledge, this is the first time that the effects of capsaicin on the third trophic level are examined.

\section{Material and methods}

\section{Chili fruits}

Chili fruits were purchased from a local market in Neuchâtel, Switzerland. We selected three varieties based on their known pungency level: non-pungent variety Padron (C. annuит), mild variety Cayenne (C. annuиm) and highly pungent variety, Habanero (C. chinense). These varieties are originally from Latin America (Muñoz-Ramírez et al. 2018), except for Padron, which was selected in Galicia, Spain (Katz 2009). These varieties were used in all the experiments with fruits.

\section{Insects}

Spodoptera latifascia, commonly known as the Velvet armyworm, occurs naturally throughout Mexico and Central America (Saunders et al. 1988; Zagatti et al. 1995). It is a polyphagous insect whose host range includes several crops such as potato, cotton, soybeans, maize, and beans (Cuny et al. 2018; Habib et al. 1982). Larvae have been frequently found feeding on leaves of chili plants in Mexico (Traine et al. 2020).

Euplectrus platyhypenae is a gregarious koinobiont ectoparasitoid, originated from Mexico, and parasitizes third and fourth instars of Noctuid and Geometrid caterpillars (Muniappan et al. 2004; Murúa and Virla 2004; Swezey 1924). Prior to oviposition, female wasps inject a venom on the dorsum of the caterpillar to inhibit molting without killing their host. One female lays up to 20 eggs that develop on the dorsal segments of the host's body feeding on its haemolymph (Coudron et al. 1990; Nakamatsu and Tanaka
2003). Before pupation, the parasitoid larvae use their saliva to kill the host and move underneath the cadaver to pupate (Nakamatsu and Tanaka 2004). Approximately one-week later adults emerge (Nakamatsu and Tanaka 2003).

Colonies of S. latifascia and E. platyhypenae were established with insects originally collected from beans, squash, and chili pepper in the experimental campus of the Universidad del Mar, in Puerto Escondido, (Oaxaca, Mexico; $\left.15^{\circ} 55^{\prime} 33.3^{\prime \prime} \mathrm{N}, 97^{\circ} 09^{\prime} 03.0^{\prime \prime} \mathrm{W}\right)$. Then, they were reared at the University of Neuchâtel under quarantine conditions, level $3\left(26^{\circ} \mathrm{C}, 60 \%\right.$ relative humidity and L12:D12). Caterpillars were fed on artificial diet (soy-wheat germ diet, Frontier scientific services, USA) in plastic boxes $(13 \times 15 \times 5 \mathrm{~cm})$ with fabric mesh for aeration. Parasitoids were reared on two different species, S. latifascia and S. frugiperda third instar caterpillars, which were fed with artificial diet and maize leaves were offered to maximize caterpillar survival until parasitoid pupation. Parasitoid adults were kept in $30 \times 30 \times 30 \mathrm{~cm}$ mesh cages (Bioquip Products) with water and honey as food source.

\section{Quantification of capsaicinoids in chili fruits and herbivore haemolymph}

To verify the pungency level of the fruits of the selected varieties, we quantified the capsaicinoids content in chili fruits. Whole fruits were oven dried for $48 \mathrm{~h}$ at $60{ }^{\circ} \mathrm{C}$ following the method developed by Collins et al. (1995). Once dried, each fruit was ground separately with a mortar to obtain a fine powder and $10 \mathrm{mg}$ was extracted with $1 \mathrm{ml}$ of methanol. The mixture was then centrifuged for $5 \mathrm{~min}$ at 14 $000 \mathrm{rpm}, 700 \mathrm{ul}$ of supernatant was collected and further diluted $100^{\prime} 000$-fold prior to HPLC analysis. For each variety, we had 10 replicates ( 1 replicate $=1$ fruit).

To investigate whether capsaicinoids can be sequestered to other tissues apart from the gut, we measured the capsaicin content in the haemolymph of S. latifascia caterpillars fed for 7 days on the three chili fruit varieties (non-pungent variety Padron, mild variety Cayenne and highly pungent variety Habanero). The haemolymph was collected by puncturing the cuticle at the dorsal part of the thorax. From each larva, we collected $2 \mu \mathrm{l}$ of haemolymph exuded immediately after the incision in an Eppendorf tube containing $10 \mu \mathrm{l}$ of an anticoagulant solution composed of $98 \mathrm{mM} \mathrm{NaOH}, 186 \mathrm{mM}$ $\mathrm{NaCl}, 17 \mathrm{mM}$ Na2EDTA and $41 \mathrm{mM}$ citric acid (pH 4.5) (Haine et al. 2007). We had five replicates per treatment and each replicate was a pool of two caterpillars. Then, $400 \mu \mathrm{l}$ of methanol $(100 \%)$ was added to each sample that were centrifuged for $5 \mathrm{~min}$ at $14000 \mathrm{rpm}$ and the supernatants were filtered using a hydrophilic PTFE filter (size $=13 \mathrm{~mm}$; Thermo Fisher Scientific) and a single-use-syringe ( $1 \mathrm{ml}$, Soft Ject). The samples were diluted 1000-fold with methanol (100\%) 
prior to analysis and they were kept at $-80{ }^{\circ} \mathrm{C}$ until further analysis.

The capsaicinoid content was analysed using an Acquity ultra-high-pressure liquid chromatography (UHPLC) system coupled to a Synapt G2 QTOF mass spectrometer (Waters, Milford, MA, USA) controlled by Masslynx 4.1. The separation was performed on a Waters Acquity BEH C18 column $(50 \times 2.1 \mathrm{~mm}$ i.d., $1.7 \mu \mathrm{m}$ particle size $)$ thermostated at $25{ }^{\circ} \mathrm{C}$. Mobile phases consisted of water containing $0.05 \%$ formic acid (solvent $\mathrm{A}$ ) and acetonitrile containing $0.05 \%$ formic acid (solvent B). Standards of capsaicin ( $>95 \%$ from Capsicum spp,) and dihydrocapsaicin ( $>85 \%$ from capsicum spp.) from Sigma-Aldrich (St. Louis, Missouri) were used to identify and quantify capsaicinoids in fruits and in the haemolymph of $S$. latifascia caterpillars. Standard curves were prepared using concentrations of 0.04, 0.2, 1 and $5 \mathrm{ug} /$ $\mathrm{ml}$.

\section{Bioassays}

To investigate the impact of capsaicin on the performance of the herbivore S. latifascia and the parasitoid E. platyhypenae, we fed caterpillars separately on chili fruits and capsaicin-spiked artificial diet.

\section{Effect of pungency level on the performance of the herbivore Spodoptera latifascia}

Caterpillars were fed on mature chili fruits from three different varieties: non-pungent variety Padron, mild variety Cayenne and highly pungent variety Habanero. Three-dayold larvae were individually placed, with a piece of fruit containing the placenta part, in a small cylindrical plastic container $(0.23 \mathrm{~L})$ covered with mesh for aeration. New fresh fruits were provided for larvae every other day. The number of replicates (plastic containers) used for each variety is as follows: non-pungent $=20$, mild $=18$, and highly pungent $=17$. The parameters recorded were: caterpillars weight until they pupate, pupation (number of pupae/number of remaining larvae) $* 100$ ), pupal weight measured $24 \mathrm{~h}$ after pupation, and adult emergence (number of adults/ number of remaining larvae)*100). The measurements were taken every three days for caterpillar weight until pupation and then every day until adult emergence. Larval and pupal weights were measured using an electronic balance (BP 161P, Sartorius, Goettingen, Germany).

To determine the effect of capsaicin alone, without other possible effects of the chili fruits, we conducted a parallel experiment with artificial diet (Soy-wheat germ diet, Frontier scientific services) spiked with capsaicin. Larvae were reared on diet with three different levels of synthetic capsaicin to mimic the gradient of pungency used for the chili fruit experiment: control (without capsaicin), low-capsaicin $\left(20 \mathrm{ppm}=0,02 \mathrm{mg} \mathrm{g}^{-1}\right)$ and high-capsaicin $\operatorname{diet}\left(200 \mathrm{ppm}=0,2 \mathrm{mg} \mathrm{g}^{-1}\right)$. The number of replicates used for each capsaicin treatment is as follows: no-capsaicin $=17$, $20 \mathrm{ppm}=19$, and $200 \mathrm{ppm}=18$. The capsaicin-spiked diet for the feeding experiment was prepared by adding two different concentrations of capsaicin ( $\geq 95 \%$ from Capsicum spp. from Sigma-Aldrich, Switzerland) dissolved in ethanol and mixed at $20 \mathrm{ppm}$ and $200 \mathrm{ppm}$ with the diet before solidification. For the control treatment, only ethanol was added. Due to the very irritating nature of pure capsaicin, we could not mimic the exact levels as found in Habanero fruits. However, we used concentrations of capsaicin that have been proven effective in other studies with Noctuidae species (Ahn et al. 2011a). We carried out this experiment using the same protocol as for the experiment with fruits (Sect. 1a).

\section{Effect of pungency level on the performance of the parasitoid Euplectrus platyhypenae}

To investigate whether the pungency level in chili fruit affects the third trophic level, the performance of $E$. platyhypenae was assessed when reared on S. latifascia larvae fed on the three chili varieties (Padron = non-pungent, Cayenne $=$ mild and Habanero $=$ highly pungent $)$. For the control treatment $(N=10)$, larvae were fed on a maize leaf with a piece of artificial diet to assure optimal oviposition by the wasp E. platyhypenae (Traine et al. 2020).

Caterpillars were reared individually for 6 days on the three varieties. On day seven, one fourth-instar caterpillar was placed on a piece of fruit from its rearing variety and placed in a $9 \times 2 \mathrm{~cm}$ Petri dish. Subsequently, one couple of E. platyhypenae were introduced in the Petri dish. The food source for the caterpillars (host) was present during the whole period of exposure to the parasitoids. Thirteen replicates (Petri dishes) were used for each variety. The average time for parasitism was between three and four days. As soon as the first clutch of eggs was observed on the larvae, the adults of E. platyhypenae were removed. Afterward, we recorded parasitism (number of parasitized larvae/number of remaining larvae)*100) and the clutch size defined as the number of eggs laid in a single reproductive bout (Godfray 1994). For each parasitized larva, the number of eggs laid by the wasp was counted using a hand lens (Triplet, 30X-21 mm).

In a parallel experiment, we followed the same procedure but removed the fruits and replaced them with no-capsaicin artificial diet when the caterpillars (host) were exposed to the parasitoids. This allowed us to test whether female wasps were capable of perceiving the capsaicin present in the host haemolymph. We recorded the same parameters as in the previous experiment. Five replicates (Petri dishes) were used for each variety. 
The goal of this experiment was to determine the effect of capsaicin alone on the parasitoid response independent of other potential fruit factors. We used artificial diet spiked with capsaicin at three different concentrations 0,20 and $200 \mathrm{ppm}$. The same protocol as for the experiment with fruits was used. In a first experiment, larvae were fed on their original capsaicin-spiked diet (capsaicin diet) before and after the exposure to the wasps. In a second experiment, the capsaicin-spiked diet was replaced by a common diet without capsaicin (no-capsaicin diet) only when caterpillars were exposed to the wasp. The purpose of these two different designs was to examine whether female wasps can perceive the capsaicin present in the host haemolymph independently when fruits were not present. In both experiments, five replicates (Petri dishes) were used for each capsaicin treatment.

\section{Statistical analysis}

All statistical analyses were performed in R statistical software (version 3.5.3; R Development Core Team 2020) by using ANOVA, followed by residual analysis to verify suitability of distributions of the tested models. To test the effect of capsaicin on caterpillars' weight, when feeding on either chili fruits or on artificial diet spiked with synthetic capsaicin, generalized linear mixed models (GLMMs) with a Gaussian distribution were used. GLMMs included 'treatment', 'time' and the interactions between 'treatment' and 'time', replicate and time as random factors. Least squares means (LSMeans) were used to compare significantly differences among treatments. Generalized linear models (GLMs) with a Gaussian distribution were used to verify the pupal weight, parasitoid clutch size, capsaicinoid contents in fruits and haemolymph. Least squares means (LSMeans) were used to compare significantly differences among treatments. Parasitoid emergence, herbivore pupation rate and adult emergence were analysed using generalized linear models (GLM) under binomial distribution. The effects of treatments on caterpillar's pupation time were analysed using the package "Survival" from R under Weibull distribution. The overdispersion of the data was verified and if necessary, the correction by using quasibinomial was applied. The sample size and number of replicates for all experiments are indicated directly in figure captions.

\section{Results}

\section{Quantification of capsaicinoid in fruits}

Capsaicinoid analysis of the chili fruits showed considerable quantitative variation among the three chili varieties both in capsaicin and dihydrocapsaicin levels (Fig. 1, capsaicin $\mathrm{F}_{[2,33]}=79.138$, d.f $=2, P<0.001$ and dihydrocapsaicin; $\mathrm{F}_{[2,33]}=73.585$, d.f $\left.=2, P<0.001\right)$. The Habanero variety had 11 and 22 times more capsaicin and dihydrocapsaicin (capsaicin: $17.89 \mathrm{mg} \mathrm{g}^{-1}$ of dry weight (DW); dihydrocapsaicin: $11.41 \mathrm{mg} \mathrm{g}^{-1} \mathrm{DW}$ ), respectively, than the mild Cayenne variety (capsaicin: $1.53 \mathrm{mg} \mathrm{g}^{-1} \mathrm{DW}$; dihydrocapsaicin:
Fig. 1 Mean $( \pm$ SEM) capsaicinoids content $(\mathrm{mg} / \mathrm{g}$ of DW) in the three chili varieties, Padron, Cayenne and Habanero. Difference among treatments is indicated by different letters for capsaicin and stars for the dihydrocapsaicin concentrations (F-test, Tukey post hoc test with Bonferroni correction: $P<0.001, N=10$ )

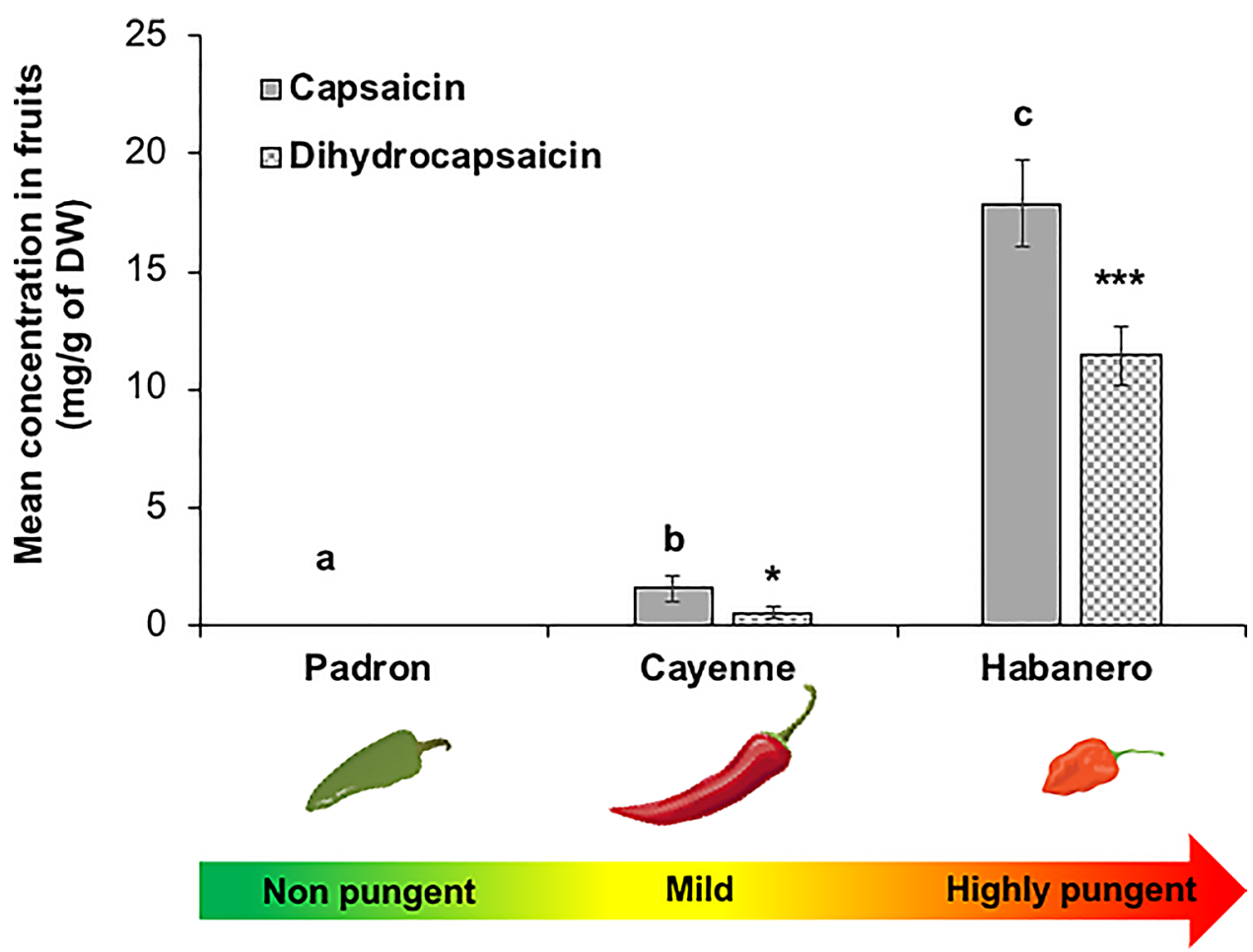


(a)

.... Non pungent $-\curvearrowleft$ Mild $\longrightarrow$ Highly pungent

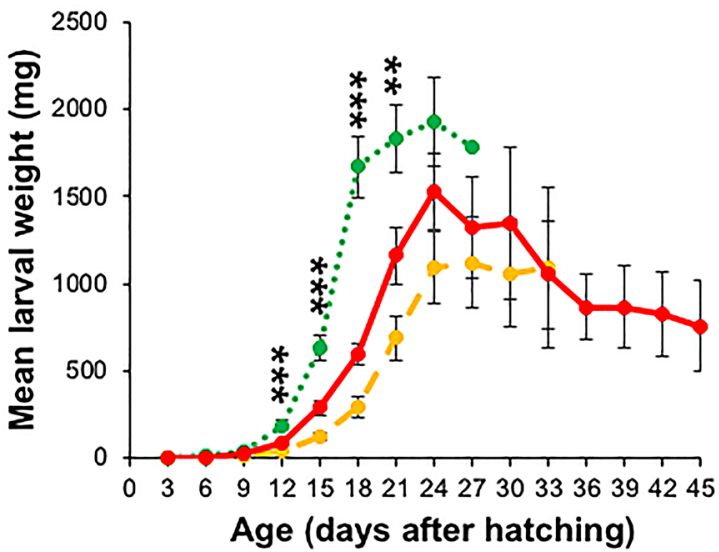

(b)
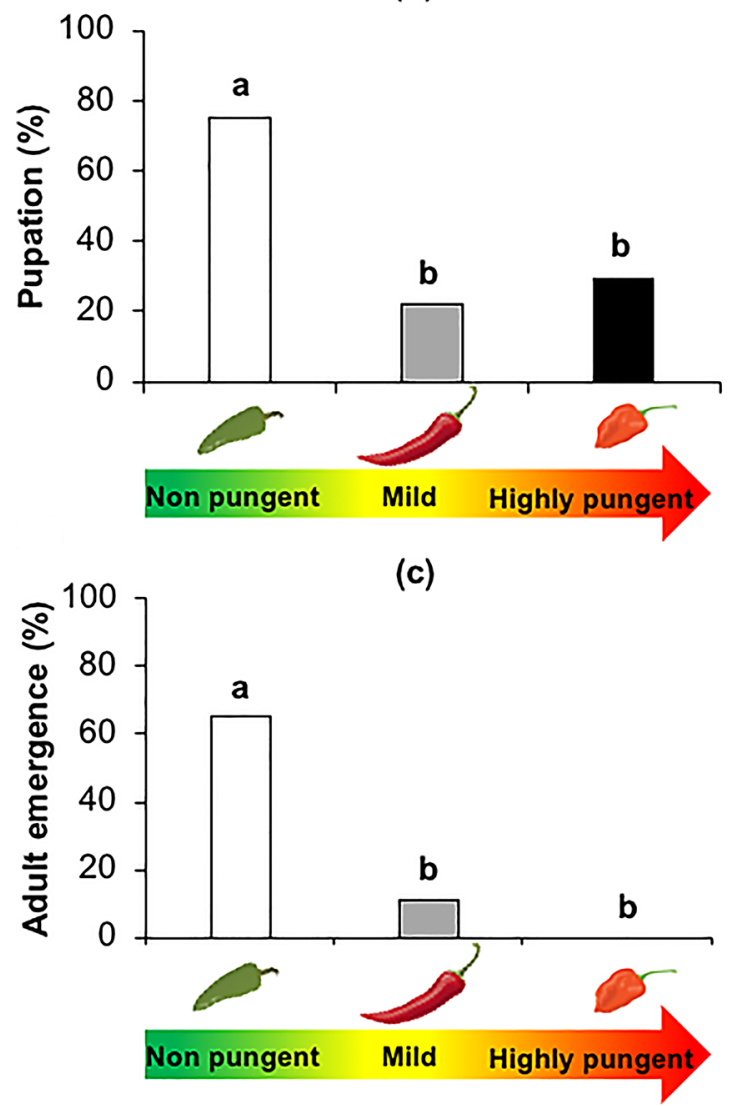

Fig. 2 Effect of pungency level (in fruits) and capsaicin content (in diet) on the performance of Spodoptera latifascia: a mean larval weight (mg), b pupation (\%) and c adult emergence (\%) of $S$. latifascia feeding on chili fruits with three different pungency levels non-pungent, mild, and highly pungent, $\mathbf{d}$ mean larval weight (mg), e pupation (\%) and $\mathbf{f}$ adult emergence (\%) of caterpillars feeding on artificial diet mixed with three levels of synthetic capsaicin (no capsaicin, 20 and $200 \mathrm{ppm}$ ). Means in a for the same age capped with (d)

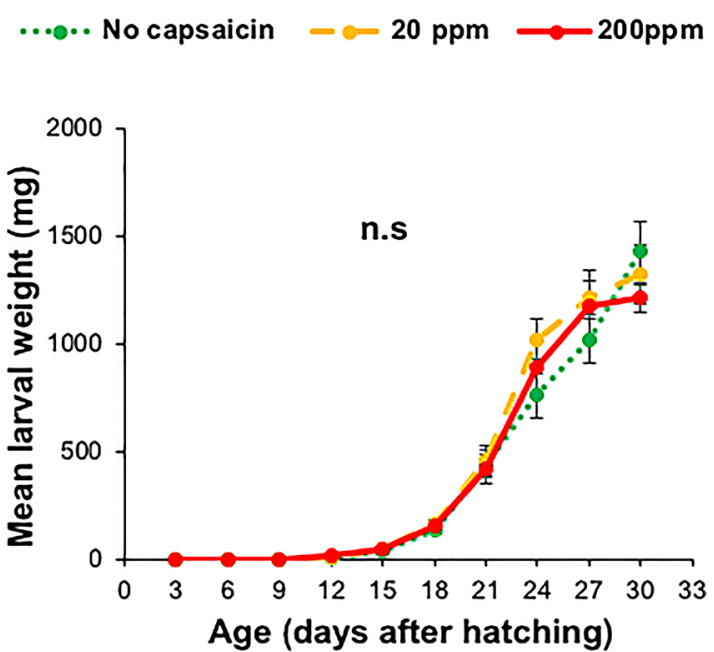

(e)
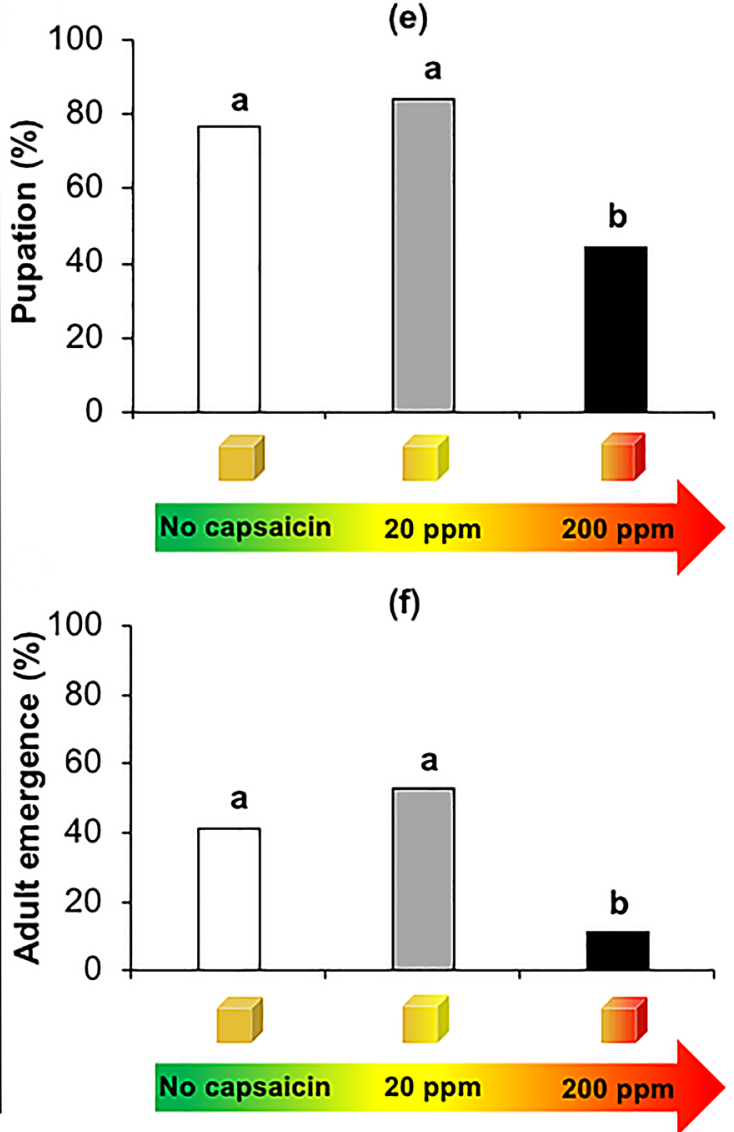

asterisks are significantly different (F-test, Tukey post hoc test with Bonferroni correction: ** $P<0.01, * * * P<0.001)$. Different letters indicate a significant difference between treatments for pupation and adult emergence (Chi-test, Tukey post hoc test with Bonferroni correction: $P<0.01$ ). Sample sizes: Fig. $2 \mathrm{a}, \mathrm{b}$ and $\mathrm{c}$, non-pungent $=20$, mild $=18$ and highly pungent $=17$; Fig. $2 \mathrm{~d}$, e and f, no-capsaicin $=17$, $20 \mathrm{ppm}=19$ and $200 \mathrm{ppm}=18$ 
$0.51 \mathrm{mg} \mathrm{g}^{-1} \mathrm{DW}$ ), whereas the Padron variety had no capsaicinoids at all (Fig. 1). In the case of Habanero and Cayenne, capsaicin content was around 1.5 and 3 times higher than dihydrocapsaicin, respectively (Fig. 1).

\section{Effect of pungency level on the performance of the herbivore Spodoptera latifascia}

The performance of caterpillars of S. latifascia was negatively affected by the pungency levels in the fruits. Caterpillars grew larger (Fig. $2 \mathrm{a}, \chi^{2}=47.492$, d.f $=2, P<0.001$ ) on the non-pungent variety than on mild and highly pungent fruits. Moreover, caterpillars took only 27 days to pupate in the non-pungent variety compared to 33 and 45 days in the mild and highly pungent varieties, respectively (Fig. 2a, $\chi^{2}=45.95$, d.f $=2, P<0.001$ ).

Feeding on mild and highly pungent varieties significantly reduced the pupation rate compared to feeding on non-pungent chili fruits (Fig. $2 b, \chi^{2}=62.160$, d.f $=2$, $P<0.001)$. However, no difference among the treatments was found for the weight of pupae (Supplementary Table 1, $\mathrm{F}_{[2,21]}=0.1167$, d.f $\left.=2, P=0.89\right)$. The percentage of adult emergence for $S$. latifascia was significantly higher on the non-pungent Padron variety than on the mild variety (Fig. 2 c, $\chi^{2}=38.213$, d.f. $=2, P<0.001$ ). On the highly pungent variety, the pupae did not reach the adult stage (Fig. 2c).

Capsaicin-spiked diet did not have a significant effect on the larval weight of S. latifascia caterpillars (Fig. 2d, $\chi^{2}=4.6453$, d.f $=2, P=0.96$ ). However, pupation rate and adult emergence were negatively affected at the higher concentration of $200 \mathrm{ppm}$ (Fig. $2 \mathrm{e}, \chi^{2}=60.478$, d.f $=2$, $P=0.009$ and Fig. 2 f, $\chi^{2}=58.261$, d.f $\left.=1, P=0.001\right)$. Caterpillars that fed on a diet containing $200 \mathrm{ppm}$ of capsaicin pupated on average 35\% less than caterpillars on the capsaicin-free and 20-ppm diets (Fig. 2e). Moreover, 30\% and $41 \%$ fewer adults emerged from the 200-ppm diet treatment than from the no-capsaicin and 20-ppm treatments (Fig. 2f).

\section{Effect of pungency level on the performance of Euplectrus platyhypenae}

The pungency level in fruits had a negative effect on parasitism rate (Fig. 3a, b). Parasitism rate was 30\% lower on caterpillars reared on the highly pungent Habanero variety in the presence of fruits (Fig. $3 \mathrm{a}, \chi^{2}=57.196$, d.f $=3$, $P=0.06$ ) and $80 \%$ lower on caterpillars reared on this same variety but exposed to the wasps without the fruits (Fig. 3b, $\chi^{2}=11.506$, d.f $=3, P=0.003$ ) than on caterpillars reared on the other two varieties. There was no significant difference on parasitism rate between mild and non-pungent treatments in the presence and absence of chili fruit (Fig. 3a, b). In the absence of the chili fruit when exposed to the wasps (Fig. 3b), parasitism rates for both mild and non-pungent treatments were as high as for the control, whereas when chili fruits were present, the parasitism rate for the same treatments was around 30\% lower than the control (Fig. 3a).

Pungency level had no significant effect on the clutch size laid by E. platyhypenae on S. latifascia (Supplementary Fig. 2a, $\mathrm{F}_{[3,27]}=0.4695$, d.f $=3, P=0.70$, Supplementary Fig. $2 \mathrm{~b}, \mathrm{~F}_{[3,16]}=0.5711$, d.f $\left.=3, P=0.64\right)$.

We found similar results for parasitoids when exposed to caterpillars reared on capsaicin-spiked diets. Parasitism rate was approximately $60 \%$ lower on larvae from the highcapsaicin diet (200 ppm) than on larvae from the other two treatments (no capsaicin) and $20 \mathrm{ppm}$ (Fig. 3c, $\chi^{2}=16.510$, d.f $=3, P=0.011)$. However, in the second experiment when larvae from the three spiked-diet treatments were switched to a non-spiked artificial diet and then exposed to parasitism, this protection was lost (Fig. 3d. $\chi^{2}=6.5017$, d.f $=3$, $P=0.59$ ).

No significant difference among treatments was found for clutch size (Supplementary Fig. $2 \mathrm{c}, \mathrm{F}_{[3,15]}=3.037$, d.f $=3$, $\mathrm{P}=0.061$; Supplementary Fig. $2 \mathrm{~d}, \mathrm{~F}_{[3,20]}=1.1686$, d. $\mathrm{f}=3$, $P=0.34$ ).

\section{Quantification of capsaicinoids in the haemolymph of S. Iatifascia}

Capsaicinoids analysis in the haemolymph revealed that when caterpillars of S. latifascia were fed on habanero fruits, the levels of capsaicin and dihydrocapsaicin were 21 and 15 times, respectively, higher than when fed on fruits of the two other varieties (Fig. 4, capsaicin $\mathrm{F}_{[2,12]}=1.826, P=0.20$ and dihydrocapsaicin; $\left.\mathrm{F}_{[2,12]}=1.3937, P=0.28\right)$. Despite these very clear differences, the results were not significant most likely due to the high variability among larvae in the amount of placenta consumed, as capsaicinoids are mostly concentrated in this tissue and not in the rest of the fruit.

\section{Discussion}

The aim of our study was to investigate the effect of capsaicin in domesticated chili peppers on a tritrophic interaction with the generalist herbivore $S$. latifascia and its ectoparasitoid E. platyhypenae. Overall, our results reveal that capsaicin had a negative effect on both insects, particularly at high concentrations. Indeed, we found that when larvae of S. latifascia were reared on pungent chili varieties, they had lower larval weight, reduced pupation, and lower adult emergence rates than when caterpillars were reared on nonpungent varieties. Similar results were found when caterpillars where reared on capsaicin-spiked and control diets. The negative effects of capsaicin subsequently affected the third trophic level by reducing the parasitism of caterpillars when these were reared on fruits or diet. 
(a)

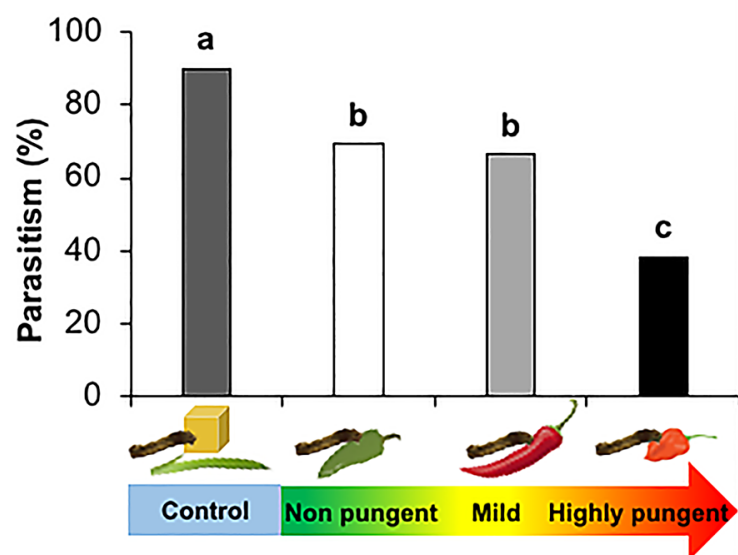

(b)

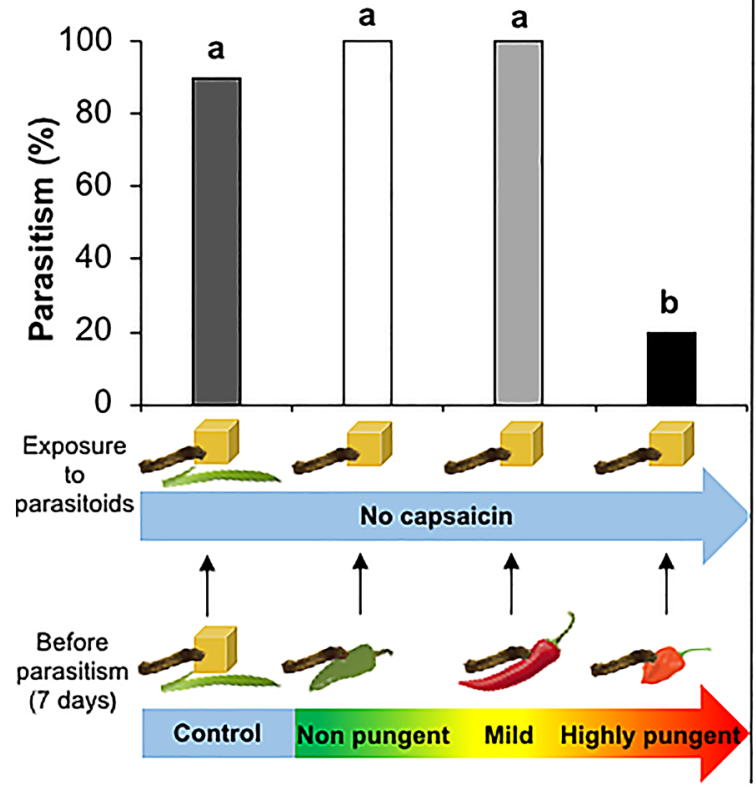

Fig. 3 Parasitism rate (\%) of Euplectrus platyhypenae on Spodoptera latifascia caterpillars feeding on a control diet and on chili fruits with three different pungency levels non-pungent, mild, and highly pungent, $\mathbf{b}$ on control diet and on chili fruits for 7 days and transferred to a regular artificial diet when exposed to the parasitoids, c a control diet and artificial diet mixed with three levels of synthetic capsaicin (no capsaicin, 20 and $200 \mathrm{ppm}$ ) and $\mathbf{d}$ a control diet and a capsaicin-spiked diet for 7 days before the parasitism and regular (c)

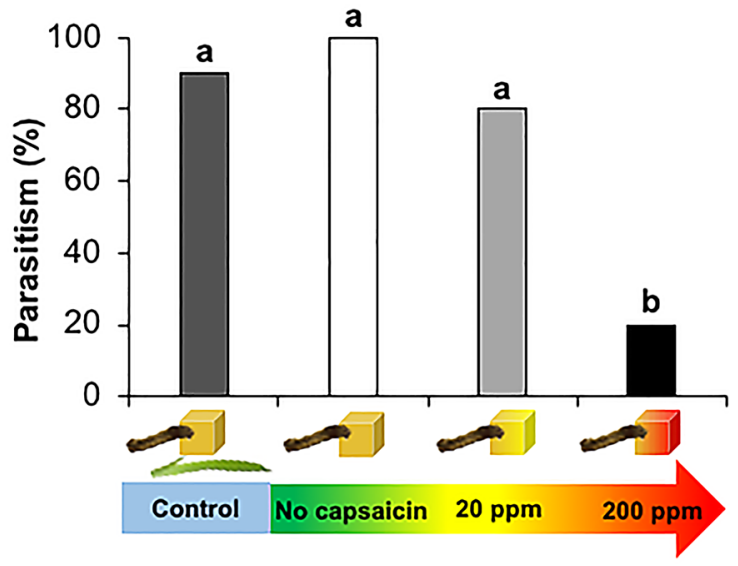

(d)

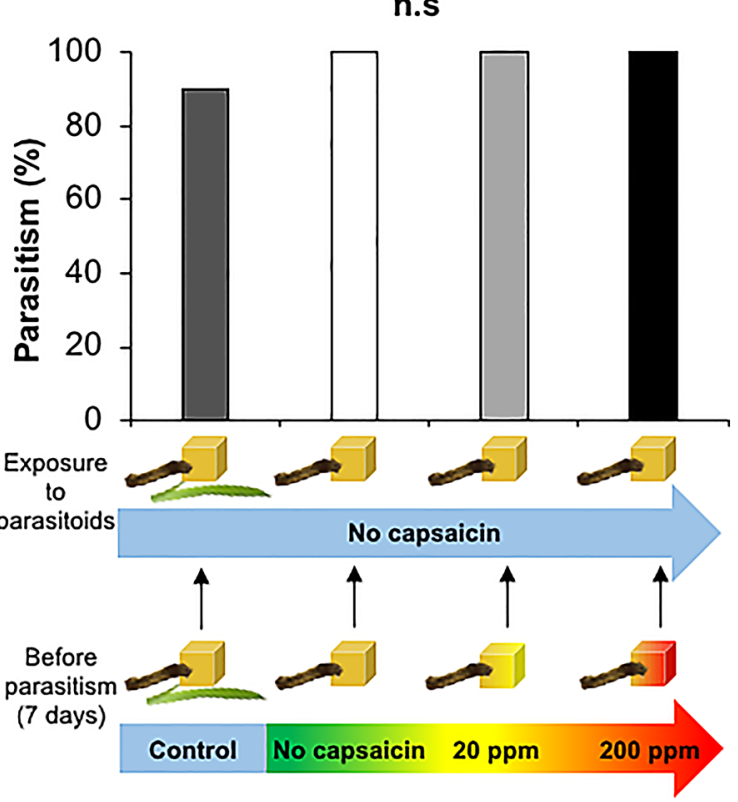

artificial diet when adding the parasitoids. For the control treatment, S. latifascia fed on maize leaf and regular artificial diet. Different letters indicate a significant difference between treatments (Chi-test, Tukey post hoc test with Bonferroni correction: $P<0.01$ ). Sample sizes: Fig. 3 a control $=10$, non-pungent $=13$, mild $=13$ and highly pungent $=13$; Fig. $3 \mathrm{~b}, \mathrm{c}$ and $\mathrm{d}, N=5$ for all treatments except for the control $(N=10)$ 
Fig. 4 Mean ( \pm SEM) capsaicinoids content (mg/g of DW) in the haemolymph of Spodoptera latifascia larvae when feeding on three chili varieties, Padron, Cayenne and Habanero. (F-test: $P>0.01, N=5$ )

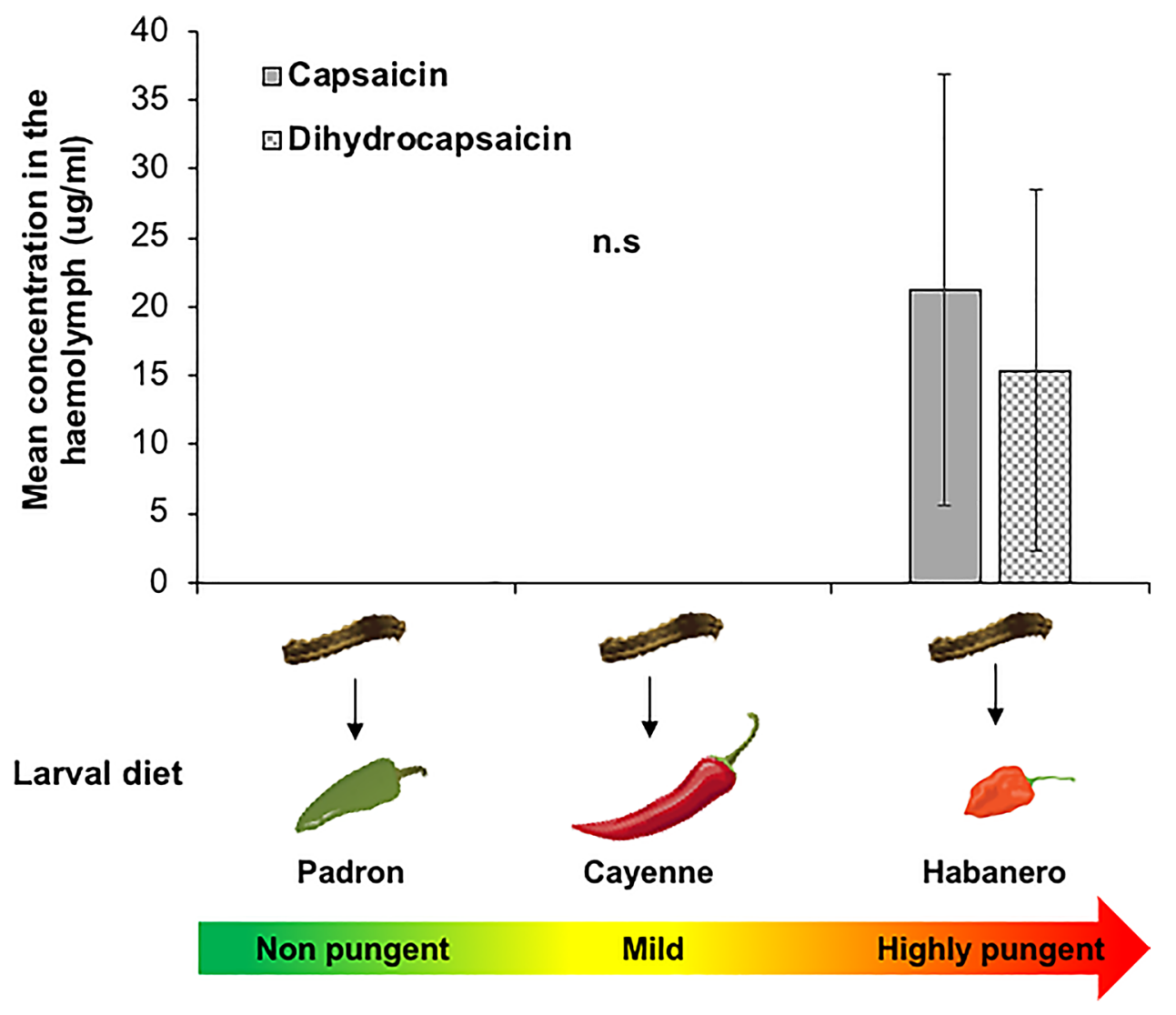

To date, all published studies on the effects of capsaicin on insects have focussed only on herbivores and most of these have used artificial diet or ground chili powder and not fresh fruits. These studies have mainly examined the benefits of capsaicin as a pesticide. For example, Cowles et al. (1989) found that oviposition of the onion fly (Delia antiqua) (Diptera: Anthomyiidae) was reduced by $99.8 \%$ and $95 \%$, respectively, by applying both chili powder and synthetic capsaicin to artificial diet. Interestingly, despite capsaicinoids being naturally absent in leaves and vegetative organs of chili plants (Estrada et al. 2002), they are still effectively used as biopesticides against sucking insects attacking chili leaves, such as the green aphid Myzus persicae Sulz (Hemiptera: Aphididae) (Edelson et al. 2002; Koleva-Gudeva et al. 2013) or whiteflies, a major pest of pepper crops (Greer 2000). However, their mode of action remains unclear.

By using fresh chili fruits, we were able to assess the effect of natural capsaicin on the second and third trophic levels. Alternatively, the capsaicin-spiked diet allowed us to isolate the effect of capsaicin from other potential effects of the chili fruits on the insects. However, some differences were observed when using these two types of diets, particularly for the herbivore, where the negative effects of capsaicin were more evident when fed on fruits. We found that pungency level in fruits had a negative effect of on the parasitism both when the fruit was present or absent.
However, with diet this effect was only evident when the spiked-capsaicin diet was removed (Fig. 3d) as compared to when it was still present during parasitism (Fig. 3c). It is possible that due to a lower amount of capsaicin in diet as compared to fruits, the lasting effects inside the host were shorter and parasitoids were not able to perceive it. Due to the high capsaicin content in the fruits, we could not mimic the exact levels because of the high toxicity we experienced while manipulating the pure synthetic capsaicin. Therefore, we would expect that the effect would be stronger if we increase the capsaicin content levels equivalent to those found in the fruits.

It is expected that the effects of capsaicin will be different on generalist than specialist herbivores. For instance, larval growth of the generalist herbivores Spodoptera frugiperda, Heliothis virescens and Helicoverpa zea (Lepidoptera: Noctuidae) was slower when fed with capsaicin-spiked diet, while the growth and survival of larvae of the tobacco budworm (Helicoverpa assulta) (Lepidoptera: Noctuidae), a specialist on Solanaceae, was not affected (Ahn et al. 2011a). The latter is considered to be one of the few insect herbivores capable of feeding on hot pepper fruits (Baek et al. 2009) and able to detoxify these secondary metabolites (Ahn et al. 2011b). Another species known to feed on chili pepper is the pepper weevil, Anthonomus eugenii (Coleoptera: Curculionidae), a specialist primarily on fruits of Capsicum spp., but 
able to feed on other nightshade plants (e.g. eggplants) (Rodriguez-Leyva 2006). This beetle is known to feed on highly pungent chili varieties such as Habanero and Scotch Bonnet (Seal and Martin 2016). Adults lay eggs on flower buds and complete their development inside the fruits (Riley and Sparks Jr 1995). Both larvae and adults were observed feeding on the fruit's placenta (Chabaane, personal observation) where capsaicinoids are concentrated (Fujiwake et al. 1982). It is assumed that both larvae and adults of this species can handle the spiciness, but the mechanism remains unclear. In our study, even though S. latifascia is a generalist, caterpillars were able to tolerate diet and fruits with medium levels of capsaicin. We found that while feeding, caterpillars can sequester capsaicin in the haemolymph, but only when they feed on the highly pungent varieties (Fig. 4). However, when exposed to lower levels of capsaicin, sequestration did not occur, or the levels were under the detection limit. It is possible that caterpillars are able to detoxify or excrete this secondary metabolite when present at low levels as it has been shown for other herbivores exposed to nicotine, also an alkaloid (Barbosa et al. 1986).

The effect of capsaicin on S. latifascia was stronger than on its parasitoid E. platyhypenae. For the parasitoid, we found differences among treatments only for parasitism rate but not for clutch size. Yet, as the parasitoid larvae feed on the host's haemolymph (Coudron et al. 1990; Nakamatsu and Tanaka 2003) where the capsaicin can be found, we could expect to find stronger effects of capsaicin on the parasitoid larval and adult stages. Thus, further studies should focus beyond the oviposition response of the parasitoid and examine the effects of capsaicin throughout parasitoid development, adult survival, size, and sex ratio. Moreover, parasitism rate was also reduced when Habanero fruits were replaced by no-capsaicin diet during the exposure to wasps. This was probably caused by the capsaicinoids accumulated in the haemolymph. However, it remains to be investigated how long this accumulation will last, and the subsequent effects on the parasitoid once the exposure to capsaicin is stopped. It would also be interesting to test the effects of capsaicin on other natural enemies with different life history strategies and feeding modes such as endoparasitoids and predators.

Recently, a growing number of studies have examined the relationship between plant chemical defence as a result of domestication and insect performance (Chen et al. 2015; Whitehead et al. 2017). It is often found that lower chemical defence results in increased performance, but there are also many exceptions to this pattern (Shlichta et al. 2018; Turcotte et al. 2014). Chili pepper offers a unique model to examine this relationship, since we have varieties selected for lower capsaicinoid content than the wild chiltepin, but also varieties that were selected for much higher pungency levels (Scoville 1912). In another study, we found that the capsaicinoid levels in chiltepin fruits collected from different populations along the Pacific coast of the state of Oaxaca, Mexico, mainly ranged between the contents detected on Habanero and Cayenne varieties (Chabaane et al., unpublished results). Thus, we would expect that the performance of S. latifascia larvae on wild chili fruits would be intermediate compared to the highly pungent and mild varieties.

Here, we focussed on the effects of capsaicin, the main plant trait targeted during varietal selection of chili pepper (Paran and van der Knaap 2007). Yet, the domestication syndrome of Capsicum species includes other traits such as germination rate, fruit colour, position and size, foliar and phenological traits (Pickersgill 2016). It is likely that some or most of these traits will also affect insect choice and performance. Moreover, some of these traits might be correlated to the level of pungency in fruits. For example, Taiti et al. (2019) found that volatile organic compound (VOC) emissions from fresh chili fruits were correlated with their spiciness. It is known that parasitoids use plant volatiles to locate their hosts (Turlings et al. 1990; Vet and Dicke 1992). Therefore, future studies should investigate the influence of multiple domesticated traits on tritrophic interactions of this important crop.

Our results also offer further insight into alternative strategies for pest management in chili pepper, one of the top ten vegetable crops in the world (FAOSTAT 2020). The use of mixed varieties in agriculture has been shown to reduce pest pressure by slowing the spread of insects via resistant varieties acting as barriers (Barot 2017). For example, Abdala-Roberts et al. (2015) showed that mixed genotypes of Capsicum chinense reduced damage of the leaf mining fly (Liriomyza trifolii) (Diptera: Agromyzidae) by 25\% as compared to monoculture. They suggest that plant genotypic diversity of their varieties (e.g. plant size, architecture, flowering phenology, and fruit size) played an important role in reducing insect attack. The importance of genotype diversity in chili peppers was also reported to decrease infestation by whitefly (Bemisia tabaci) (Hemiptera: Aleyrodidae) and yellow mite (Polyphagotarsonemus latus) (Acari: Tarsonemidae) (Datta and Chakraborty 2013), as well as black aphid (Aphis craccivora) (Homoptera: Aphididae) (Ofori et al. 2015) infestations on peppers. In this context, our results suggest that growing mixed chili varieties with different pungency levels, in addition to the use of parasitoids, might reduce pest pressure by generalist herbivores. Therefore, chili pepper farmers should include these practices in their IPM (Integrated pest management) programmes to optimize pest control.

In conclusion, our study represents pioneering work regarding the effect of natural capsaicin on herbivores and the third trophic level. In the future, this knowledge could also be important for other crops, such as hot tomato, which could be developed by activating the inactive capsaicinoid 
biosynthesis pathway naturally present in this Solanaceous crop (Naves et al. 2019). Moreover, as chili peppers originate and were domesticated in Mesoamerica, by studying its interactions with native insects from this region, our results could provide insight into the selective pressures that have contributed to the crop's phenotypic diversity and the relationship with its wild ancestor.

\section{Author contributions}

$\mathrm{YC}$ and $\mathrm{BB}$ conceived and designed the research. YC performed experiments. YC and CMA developed the methods. YC and CMA analysed the data. GG performed the chemical analyses. YC and BB wrote the first drafts. All authors contributed to the last versions of the manuscript.

Supplementary Information The online version contains supplementary material available at https://doi.org/10.1007/s10340-021-01399-8.

Acknowledgements We thank Diane Laplanche and Gaia Besomi for helping with capsaicinoid extraction. This research was financially supported by a grant from the Swiss National Science Foundation (project no. 31003A-162860) awarded to Betty Benrey. The authors declare that they have no conflict of interest.

Funding Open Access funding provided by Université de Neuchâtel.

Open Access This article is licensed under a Creative Commons Attribution 4.0 International License, which permits use, sharing, adaptation, distribution and reproduction in any medium or format, as long as you give appropriate credit to the original author(s) and the source, provide a link to the Creative Commons licence, and indicate if changes were made. The images or other third party material in this article are included in the article's Creative Commons licence, unless indicated otherwise in a credit line to the material. If material is not included in the article's Creative Commons licence and your intended use is not permitted by statutory regulation or exceeds the permitted use, you will need to obtain permission directly from the copyright holder. To view a copy of this licence, visit http://creativecommons.org/licenses/by/4.0/.

\section{References}

Abdala-Roberts L, Berny-Mier y Terán JC, Moreira X, Durán-Yáñez A, Tut-Pech F (2015) Effects of pepper (Capsicum chinense) genotypic diversity on insect herbivores. Agric For Entomol 17:433438. https://doi.org/10.1111/afe.12125

Ahn S-J, Badenes-Pérez FR, Heckel DG (2011a) A host-plant specialist, Helicoverpa assulta, is more tolerant to capsaicin from Capsicum annuum than other noctuid species. J Insect Physiol 57:1212-1219. https://doi.org/10.1016/j.jinsphys.2011.05.015

Ahn SJ, Badenes-Pérez FR, Reichelt M, Svatoš A, Schneider B, Gershenzon J, Heckel DG (2011b) Metabolic detoxification of capsaicin by UDP-glycosyltransferase in three Helicoverpa species. Arch Insect Biochem Physiol 78:104-118. https://doi.org/10.1002/arch. 20444

Argaez LGB, Salazar FFM, Zuñiga FZ, Estrada TG, Flores IRI (2009) Characterization of a Capsicum chinense seed peptide fraction with broad antibacterial activity. Asian J Biochem 4:77-87. https://doi.org/10.3923/ajb.2009.77.87

Aza-González C, Núñez-Palenius HG, Ochoa-Alejo N (2011) Molecular biology of capsaicinoid biosynthesis in chili pepper (Capsicum spp.). Plant Cell Rep 30:695-706. https://doi.org/10.1007/ s00299-010-0968-8

Baek S, Cho K, Song YH, Lee J-H (2009) Sampling plans for estimating pepper fruit damage levels by oriental tobacco budworm, Helicoverpa assulta (Guenee), in hot pepper fields. J Asia-Pac Entomol 12:175-178. https://doi.org/10.1016/j.aspen.2009.03.003

Barbosa P, Saunders J, Kemper J, Trumbule R, Olechno J, Martinat P (1986) Plant allelochemicals and insect parasitoids effects of nicotine on Cotesia congregata (say)(Hymenoptera: Braconidae) and Hyposoter annulipes (Cresson)(Hymenoptera: Ichneumonidae). J Chem Ecol 12:1319-1328. https://doi.org/10.1007/BF01012351

Barot S et al (2017) Designing mixtures of varieties for multifunctional agriculture with the help of ecology. A Rev Agron Sustain Dev 37:13. https://doi.org/10.1007/s13593-017-0418-x

Benrey B, Denno RF (1997) The slow-growth-high-mortality hypothesis: a test using the cabbage butterfly. Ecology 78:987-999. https://doi.org/10.1890/0012-9658(1997)078[0987:TSGHMH] 2.0.CO;2

Carrizo García C, Barfuss MH, Sehr EM, Barboza GE, Samuel R, Moscone EA, Ehrendorfer F (2016) Phylogenetic relationships, diversification and expansion of chili peppers (Capsicum, Solanaceae). Ann Bot 118:35-51. https://doi.org/10.1093/aob/mcw079

Chang'a A, de Souza N, Muya J, Keyyu J, Mwakatobe A, Malugu L, Ndossi HP, Konuche J, Omondi R, Mpinge A, Hahn N, Palminteri S, Olson D (2016) Scaling-up the use of chili fences for reducing human-elephant conflict across landscapes in Tanzania. Trop Conserv Sci 9:921-930. https://doi.org/10.1177/1940082916 00900220

Chen YH, Gols R, Benrey B (2015) Crop domestication and its impact on naturally selected trophic interactions. Annu Rev Entomol 60:35-58. https://doi.org/10.1146/annurev-ento-010814-020601

Cichewicz RH, Thorpe PA (1996) The antimicrobial properties of chile peppers (Capsicum species) and their uses in mayan medicine. J Ethnopharmacol 52:61-70. https://doi.org/10.1016/ 0378-8741(96)01384-0

Collins MD, Wasmund LM, Bosland PW (1995) Improved method for quantifying capsaicinoids in Capsicum using high-performance liquid chromatography. HortScience 30:137-139. https:// doi.org/10.21273/HORTSCI.30.1.137

Coudron TA, Kelly TJ, Puttler B (1990) Developmental responses of Trichoplusia ni (Lepidoptera: Noctuidae) to parasitism by the ectoparasite Euplectrus plathypenae (Hymenoptera: Eulophidae). Arch Insect Biochem Physiol 13:83-94. https://doi.org/ 10.1002/arch.940130108

Cowles R, Keller J, Miller J (1989) Pungent spices, ground red pepper, and synthetic capsaicin as onion fly ovipositional deterrents. J Chem Ecol 15:719-730. https://doi.org/10.1007/BF010 14714

Cuny MA, Gendry J, Hernández-Cumplido J, Benrey B (2018) Changes in plant growth and seed production in wild lima bean in response to herbivory are attenuated by parasitoids. Oecologia 187:447-457. https://doi.org/10.1007/s00442-018-4119-1

Datta S, Chakraborty G (2013) Studies on influence of genotypic diversity on yield, quality and incidence of white fly and yellow mite in Capsicum annuum L. J Appl Nat Sci 5:350-356. https:// doi.org/10.31018/jans.v5i2.331

Edelson JV, Duthie J, Roberts W (2002) Toxicity of biorational insecticides: activity against the green peach aphid, Myzus persicae (Sulzer). Pest Manag Sci: Former Pestic Sci 58:255-260. https://doi.org/10.1002/ps.444

El-Heneidy A, Barbosa P, Gross P (1988) Influence of dietary nicotine on the fall armyworm, Spodoptera frugiperda and its 
parasitoid, the ichneumonid wasp Hyposoter annulipes. Entomol Exp Appl 46:227-232. https://doi.org/10.1111/j.1570-7458. 1988.tb01116.x

Estrada B, Bernal MA, Díaz J, Pomar F, Merino F (2002) Capsaicinoids in vegetative organs of Capsicum annuum $\mathrm{L}$. in relation to fruiting. J Agric Food Chem 50:1188-1191. https://doi.org/10. 1021/jf011270j

FAOSTAT (2020) Global production of vegetables in 2018, by type. https://www.statista.com/statistics/264065/global-production-ofvegetables-by-type/. Accessed 12 January 2021

Fujiwake H, Suzuki T, Iwai K (1982) Capsaicinoid formation in the protoplast from the placenta of Capsicum fruits. Agric Biol Chem 46:2591-2592. https://doi.org/10.1080/00021369.1982.10865477

Gepts P (2004) Crop domestication as a long-term selection experiment. Plant Breed Rev 24:1-44. https://doi.org/10.1002/97804 70650288

Godfray HCJ (1994) Taxonomic Index. In: Parasitoids, vol 67. Behavioral and Evolutionary Ecology. Princeton University Press, pp 465-473. https://doi.org/10.2307/j.ctvs32rmp

González-Zamora A, Sierra-Campos E, Pérez-Morales R, VázquezVázquez C, Gallegos-Robles MA, López-Martínez JD, GarcíaHernández JL (2015) Measurement of capsaicinoids in chiltepin hot pepper: a comparison study between spectrophotometric method and high performance liquid chromatography analysis. J Chem 2015:10. https://doi.org/10.1155/2015/709150

Govindarajan V, Salzer UJ (1985) Capsicum-production, technology, chemistry, and quality part 1: history, botany, cultivation, and primary processing. Crit Rev Food Sci Nutr 22:109-176. https://doi. org/10.1080/10408398509527412

Greer L (2000) Greenhouse IPM: sustainable whitefly control. The National Center for Appropriate Technology (NCAT), Butte. http://michaeljbowe.com/TSG/SG/SF_00256.pdf

Haak DC, McGinnis LA, Levey DJ, Tewksbury JJ (2012) Why are not all chilies hot? A trade-off limits pungency. Proc R Soc B: Biol Sci 279:2012-2017. https://doi.org/10.1098/rspb.2011.2091

Habib M, Paleari L, Amaral M (1982) Effect of three larval diets on the development of the armyworm, Spodoptera latifascia Walker, 1856 (Noctuidae, Lepidoptera). Rev Bras De Zool 1:177-182. https://doi.org/10.1590/S0101-81751982000300007

Haine ER, Rolff J, Siva-Jothy MT (2007) Functional consequences of blood clotting in insects. Dev Comp Immunol 31:456-464. https:// doi.org/10.1016/j.dci.2006.08.004

Hedges S, Gunaryadi D (2010) Reducing human-elephant conflict: do chillies help deter elephants from entering crop fields? Oryx 44:139-146. https://doi.org/10.1017/S0030605309990093

Hori M, Nakamura H, Fujii Y, Suzuki Y, Matsuda K (2011) Chemicals affecting the feeding preference of the solanaceae-feeding lady beetle Henosepilachna vigintioctomaculata (Coleoptera: Coccinellidae). J Appl Entomol 135:121-131. https://doi.org/10. 1111/j.1439-0418.2010.01519.x

Jones NL, Shabib S, Sherman PM (1997) Capsaicin as an inhibitor of the growth of the gastric pathogen Helicobacter pylori. FEMS Microbiol Lett 146:223-227. https://doi.org/10.1111/j.1574-6968. 1997.tb10197.x

Jordt S-E, Julius D (2002) Molecular basis for species-specific sensitivity to "hot" chili peppers. Cell 108:421-430. https://doi.org/10. 1016/S0092-8674(02)00637-2

Katz E (2009) Chili pepper, from Mexico to Europe. Food, imaginary and cultural identity. Food, Imaginaries and Cultural Frontiers Essays in honour of Helen Macbeth, Guadalajara, Universidad de Guadalajara, Colección Estudios del Hombre, Serie Antropología de la Alimentación:213-232

Kim S et al (2014) Genome sequence of the hot pepper provides insights into the evolution of pungency in Capsicum species. Nat Genet 46:270-278. https://doi.org/10.1038/ng.2877
Saunders JL, Coto D, King ABS (1998) Plagas invertebradas de cultivos anuales alimenticios en América Central, 2da edición. Centro Agronómico Tropical de Investigación y Enseñanza, CATIE 29:305. http://repositorio.bibliotecaorton.catie.ac.cr/handle/ $11554 / 3346$

Koleva-Gudeva L, Mitrev S, Maksimova V, Spasov D (2013) Content of capsaicin extracted from hot pepper (Capsicum annuиm ssp. microcarpum L.) and its use as an ecopesticide. Hemijska Industrija 67:671-675. https://doi.org/10.2298/HEMIND120921110K

Ladizinsky G (2012) Plant evolution under domestication. Springer Science \& Business Media, Berlin. https://doi.org/10.1007/ 978-94-011-4429-2

Lang Y, Yanagawa S, Sasanuma T, Sasakuma T (2006) A gene encoding a putative acyl-transferase involved in pungency of Capsicum. Breed Sci 56:55-62. https://doi.org/10.1270/jsbbs.56.55

Marini E, Magi G, Mingoia M, Pugnaloni A, Facinelli B (2015) Antimicrobial and anti-virulence activity of capsaicin against erythromycin-resistant, cell-invasive group a streptococci. Front Microbiol 6:1281. https://doi.org/10.3389/fmicb.2015.01281

Mason JR, Maruniak J (1983) Behavioral and physiological effects of capsaicin in red-winged blackbirds. Pharmacol Biochem Behav 19:857-862. https://doi.org/10.1016/0091-3057(83)90093-X

Meyer RS, DuVal AE, Jensen HR (2012) Patterns and processes in crop domestication: an historical review and quantitative analysis of 203 global food crops. New Phytol 196:29-48. https://doi.org/ 10.1111/j.1469-8137.2012.04253.x

Molina Torres J, García Chávez A, Ramírez Chávez E (1999) Antimicrobial properties of alkamides present in flavouring plants traditionally used in mesoamerica: affinin and capsaicin. J Ethnopharmacol 64:241-248. https://doi.org/10.1016/s0378-8741(98) 00134-2

Muniappan R, Bamba J, Cruz J, Reddy G (2004) Biology, rearing and field release on guam of Euplectrus maternus, a parasitoid of the fruit-piercing moth, Eudocima fullonia. Biocontrol 49:537-551. https://doi.org/10.1023/B:BICO.0000036439.74117.2f

Muñoz-Ramírez LS, Peña-Yam LP, Avilés-Viñas SA, Canto-Flick A, Guzmán-Antonio AA, Santana-Buzzy N (2018) Behavior of the hottest chili peppers in the world cultivated in Yucatan, Mexico. HortScience 53:1772-1775. https://doi.org/10.21273/HORTS CI13574-18

Murúa G, Virla EG (2004) Contribution to the biological knowledge of Euplectrus platyhypenae (Hymenoptera: Eulophidae), a parasitoid of Spodoptera frugiperda (Lepidoptera: Noctuidae) in Argentina. Folia Entomológica Mexicana 43:171-180

Nakamatsu Y, Tanaka T (2003) Venom of ectoparasitoid, Euplectrus sp. near plathypenae (Hymenoptera: Eulophidae) regulates the physiological state of Pseudaletia separata (Lepidoptera: Noctuidae) host as a food resource. J Insect Physiol 49:149-159. https://doi.org/10.1016/S0022-1910(02)00261-5

Nakamatsu Y, Tanaka T (2004) Venom of Euplectrus separatae causes hyperlipidemia by lysis of host fat body cells. J Insect Physiol 50:267-275. https://doi.org/10.1016/j.jinsphys.2003. 12.005

Naves ER, de Ávila SL, Sulpice R, Araújo WL, Nunes-Nesi A, Peres LE, Zsögön A (2019) Capsaicinoids: pungency beyond Capsicum. Trends Plant Sci 24:109-120. https://doi.org/10.1016/j.tplan ts.2018.11.001

Ofori ESK, Appiah AS, Nunekpeku W, Quartey EK, Owusu-Ansah M, Amoatey HM (2015) Relative abundance and diversity of insect species on nine genotypes of pepper (Capsicum spp.) grown under field conditions in Ghana. J Exp Agric Int. https://doi.org/10.9734/ AJEA/2015/12150

Omolo MA et al (2014) Antimicrobial properties of chili peppers. J Infect Dis Ther 2:145. https://doi.org/10.4172/2332-0877.10001 45 
Opitz SE, Müller C (2009) Plant chemistry and insect sequestration. Chemoecology 19:117-154. https://doi.org/10.1007/ s00049-009-0018-6

Paran I, van der Knaap E (2007) Genetic and molecular regulation of fruit and plant domestication traits in tomato and pepper. J Exp Bot 58:3841-3852. https://doi.org/10.1093/jxb/erm257

Pickersgill B (2016) Chile Peppers (Capsicum spp.). In: Lira R, Casas A, Blancas J (eds) Ethnobotany of Mexico. Ethnobiology. Springer, New York, NY. https://doi.org/10.1007/978-1-46146669-7_17

Price PW, Bouton CE, Gross P, McPheron BA, Thompson JN, Weis AE (1980) Interactions among three trophic levels: influence of plants on interactions between insect herbivores and natural enemies. Annu Rev Ecol Syst 11:41-65. https://doi.org/10.1146/annurev. es.11.110180.000353

Riley D, Sparks AN (1995) The pepper weevil and its management. AgriLife Extension, L-5069. Texas A \& M University, BryonCollege Station, TX. Available electronically from https://hdl. handle.net/1969.1/87688

Rodriguez-Leyva E (2006) Life history of Triaspis eugenii Wharton and López-Martínez (Hymenoptera: Braconidae) and evaluation of its potential for biological control of pepper weevil Anthonomus eugenii Cano (Coleoptera: Curculionidae). Dissertation, University of Florida,

Rowell-Rahier M, Pasteels JM (1992) Chapter 6 - Third Trophic Level Influences of Plant Allelochemicals. In: Rosenthal GA, Berenbaum MR (eds) Herbivores: their interactions with secondary plant metabolites (Second Edition). Academic Press, San Diego, pp 243-277. https://doi.org/10.1016/B978-0-08-092545-5. 50011-0

Schaffner U, Boevé J-L, Gfeller H, Schlunegger UP (1994) Sequestration of Veratrum alkaloids by specialist Rhadinoceraea nodicornis Konow (Hymenoptera, Tenthredinidae) and its ecoethological implications. J Chem Ecol 20:3233-3250. https://doi.org/10. 1007/BF02033723

Scoville WL (1912) Note on capsicums. J Am Pharm Assoc 1:453-454. https://doi.org/10.1002/jps.3080010520

Seal DR, Martin CG (2016) Pepper weevil (Coleoptera: Curculionidae) preferences for specific pepper cultivars, plant parts, fruit colors, fruit sizes, and timing. Insects 7:9. https://doi.org/10.3390/insec ts 7010009

Shlichta JG, Cuny MA, Hernandez-Cumplido J, Traine J, Benrey B (2018) Contrasting consequences of plant domestication for the chemical defenses of leaves and seeds in lima bean plants. Basic Appl Ecol 31:10-20. https://doi.org/10.1016/j.baae.2018.05.012

Smartt J, Simmonds NW (1995) Evolution of crop plants (No. Sirsi) i9780470233726)

Stewart C Jr et al (2005) The pun1 gene for pungency in pepper encodes a putative acyltransferase. Plant J 42:675-688. https:// doi.org/10.1111/j.1365-313X.2005.02410.x

Swezey O (1924) The Mexican armyworm parasite (Euplectrus platyhypenae). Hawaii Plant Rec 28:318-320

Szolcsányi J, Sann H, Pierau F-K (1986) Nociception in pigeons is not impaired by capsaicin. Pain 27:247-260. https://doi.org/10.1016/ 0304-3959(86)90215-0

Taiti C, Costa C, Migliori CA, Comparini D, Figorilli S, Mancuso S (2019) Correlation between volatile compounds and spiciness in domesticated and wild fresh chili peppers. Food Bioprocess Technol 12:1366-1380. https://doi.org/10.1007/s11947-019-02297-9

Tęgowska E, Grajpel B, Piechowicz B (2005) Does red pepper contain an insecticidal compound for colorado beetle? IOBC Wprs Bull 28:121-127

Tewksbury JJ, Nabhan GP (2001) Directed deterrence by capsaicin in chillies. Nature 412:403-404. https://doi.org/10.1038/35086653

Tewksbury JJ, Reagan KM, Machnicki NJ, Carlo TA, Haak DC, Peñaloza ALC, Levey DJ (2008) Evolutionary ecology of pungency in wild chilies. Proc Natl Acad Sci 105:11808-11811. https://doi.org/10.1073/pnas.0802691105

Traine J, Cuny MA, Bustos-Segura C, Benrey B (2020) The interaction between host and host plant influences the oviposition and performance of a generalist ectoparasitoid. Entomol Exp Appl 169:133-144. https://doi.org/10.1111/eea.12949

Tsurumaki K, Sasanuma T (2019) Discovery of novel unfunctional pAMT allele pamt 10 causing loss of pungency in sweet bell pepper (Capsicum annuum L.). Breed Sci 69:133-142. https://doi. org/10.1270/jsbbs. 18150

Turcotte MM, Turley NE, Johnson MT (2014) The impact of domestication on resistance to two generalist herbivores across 29 independent domestication events. New Phytol 204:671-681. https:// doi.org/10.1111/nph.12935

Turlings TC, Benrey B (1998) Effects of plant metabolites on the behavior and development of parasitic wasps. Ecoscience 5:321333. https://doi.org/10.1080/11956860.1998.11682472

Turlings TC, Tumlinson JH, Lewis WJ (1990) Exploitation of herbivore-induced plant odors by host-seeking parasitic wasps. Science 250:1251-1253. https://doi.org/10.1126/science.250.4985.1251

Vet LE, Dicke M (1992) Ecology of infochemical use by natural enemies in a tritrophic context. Annu Rev Entomol 37:141-172. https://doi.org/10.1146/annurev.en.37.010192.001041

Weissenberg M, Klein M, Meisner J, Ascher K (1986) Larval growth inhibition of the spiny bollworm, Earias insulana, by some steroidal secondary plant compounds. Entomol Exp Appl 42:213-217. https://doi.org/10.1111/j.1570-7458.1986.tb01024.x

Whitehead SR, Turcotte MM, Poveda K (2017) Domestication impacts on plant-herbivore interactions: a meta-analysis. Philos Trans R Soc B: Biolo Sci 372:20160034. https://doi.org/10.1098/rstb. 2016.0034

Wilson W (1996) Wax and capsaicin based pesticide. J Clean Prod 1:61

Witting N, Svensson P, Gottrup H, Arendt-Nielsen L, Jensen TS (2000) Intramuscular and intradermal injection of capsaicin: a comparison of local and referred pain. PAIN® 84:407-412. https://doi. org/10.1016/S0304-3959(99)00231-6

Zagatti P, Lalanne-Cassou B, le Duchat d'Aubigny J (1995) Catalogue of the lepidoptera of the French antilles. INRA. Accessed from INRA Database. http://www7.inra.fr/papillon/indexeng.htm

Publisher's Note Springer Nature remains neutral with regard to jurisdictional claims in published maps and institutional affiliations. 